\title{
Incidence of readmission to the ICU after cardiac surgery: a systematic review and meta-analysis
}

\author{
Haiyu Lv ${ }^{1 \#}$, Zhenfa Meng ${ }^{2 *}$, Cheng Yu ${ }^{1}$, Qinghua Chen ${ }^{2}$, Yulin Wang ${ }^{2}$, Yahong Xiao ${ }^{3}$ \\ ${ }^{1}$ Department of Cardiac Surgery, Hainan General Hospital (Hainan Affiliated Hospital of Hainan Medical University), Haikou, China; ${ }^{2}$ Department \\ of Critical Medicine, Danzhou People's Hospital, Danzhou, China; ${ }^{3}$ Department of Cardiovascular Operating Room, The Second Affiliated Hospital \\ of Hainan Medical University, Haikou, China \\ Contributions: (I) Conception and design: H Lv, C Yu; (II) Administrative support: Y Xiao; (III) Provision of study materials or patients: Z Meng; (IV) \\ Collection and assembly of data: Q Chen; (V) Data analysis and interpretation: Y Wang; (VI) Manuscript writing: All authors; (VII) Final approval of \\ manuscript: All authors. \\ \#These authors contributed equally to this work. \\ Correspondence to: Yahong Xiao. Department of Cardiovascular Operating Room, The Second Affiliated Hospital of Hainan Medical University, \\ Haikou 570311, China. Email: xiaoyahong150@163.com.
}

Background: Due to the complexity of cardiac surgery, almost all patients need to be admitted to the intensive care unit (ICU) for postoperative care after surgery. After being discharged from the ICU, some patients need to be readmitted due to disease deterioration during hospitalization. We conducted a metaanalysis of the literature to investigate the incidence of readmission to the ICU in patients undergoing cardiac surgery.

Methods: The PubMed, Medline, and Elsevier databases were searched using the keywords "cardiac surgery," "readmission," "intensive care unit," and "ICU" to retrieve English-language articles published from January 2000 to January 2021. The articles were screened, and their quality was evaluated. A metaanalysis was performed on the outcomes of patients after readmission to the ICU using Stata16.0 software.

Results: Ultimately, 9 articles were included in the meta-analysis, comprising 32,825 cardiac surgery cases, of whom 1,302 were readmitted to the ICU. The incidence of readmission to the ICU was $3.97 \%$. Among the direct reasons for readmission to the ICU, respiratory failure accounted for 13.6-48.6\%, while hemodynamic instability accounted for $21.6-51.9 \%$. The results of the meta-analysis showed that the mortality rate of patients readmitted to the ICU was significantly higher than that of patients not readmitted to the ICU [risk difference $(\mathrm{RD})=8.05,95 \%$ confidence interval $(\mathrm{CI}): 5.10-12.69, \mathrm{Z}=8.965 ; \mathrm{P}<0.0001$ ], as was the length of hospital stay [standard mean difference (SMD) =3.17, 95\% CI: 1.40-4.94, Z=3.504; $\mathrm{P}<0.001$ ], and the incidence of complications (odds ratio $=1.97,95 \%$ CI: $1.35-2.87, \mathrm{Z}=3.507 ; \mathrm{P}<0.001$ ).

Conclusions: Nine articles were included in this meta-analysis on the incidence rate of readmission to the ICU of patients undergoing cardiac surgery. The results showed that the proportion of readmission to the ICU was $3.97 \%$. Patients readmitted to the ICU had a higher rate of complications, longer hospital stay, and higher mortality rate than those not readmitted.

Keywords: Cardiac surgery; intensive care unit (ICU); meta-analysis

Submitted Nov 19, 2021. Accepted for publication Dec 30, 2021.

doi: $10.21037 /$ jtd-21-1893

View this article at: https://dx.doi.org/10.21037/jtd-21-1893

(C) Journal of Thoracic Disease. All rights reserved. 


\section{Introduction}

An intensive care unit (ICU) has a number of advantages over a general ward in terms of emergency and critical care after major surgery. Due to the complexity of cardiac surgery, almost all patients need to enter the ICU for postoperative care, including patients undergoing the minimally invasive cardiac surgery (MICS) surgery, or the Thoracotomy and valve replacement surgery $(1,2)$. Some patients need to be readmitted to the ICU for care during hospitalization after leaving the ICU due to their condition deteriorating, and reports have shown that the incidence of readmission to the ICU is as high as $8 \%(3,4)$. The main causes of patients returning to ICU include asphyxia, ventricular fibrillation, hypoxemia, severe pulmonary infection, pericardial tamponade and pulmonary hypertension crisis (5). Patients readmitted to the ICU are difficult to treat, and have a higher incidence of complications and mortality comparing to those admitted to ICU for the first time (6). A meta-analysis conducted by Shawon et al. (7) had concluded that the pooled 30-day readmission rate after coronary artery bypass graft (CABG) surgery was $12.9 \%$, but surgery type in this study was limited to CABG. In our study, databases were searched to retrieve studies on patients readmitted to the ICU after all types of cardiac surgery, and the readmission rate for different type of surgery was discussed to provide better evidence. We present the following article in accordance with the MOOSE reporting checklist (available at https:// jtd.amegroups.com/article/view/10.21037/jtd-21-1893/rc).

\section{Methods}

\section{Data source and search strategy}

The PubMed, Medline, and Elsevier databases were searched using the keywords "cardiac surgery," "readmission," "intensive care unit," and "ICU" to retrieve English-language articles published between January 2000 and January 2021.

\section{Inclusion criteria}

To be eligible for inclusion in the meta-analysis, studies had to meet the following inclusion criteria: (I) be a retrospective observational cohort study; (II) comprise patients who underwent cardiac surgery, including CABG, heart valve replacement, surgery to correct a congenital heart disease, aorta surgery, and heart transplantation; (III) detail the specific reasons why patients were readmitted to the ICU (e.g., respiratory system reasons or cardiac system reasons), the number of readmissions to the ICU, and the outcomes of patients readmitted to the ICU (e.g., mortality, length of hospital stay, and complications).

\section{Exclusion criteria}

Studies were excluded from the meta-analysis if they met any of the following exclusion criteria: (I) the study was a case-control study, or reviews, case analysis, or systematic analysis which could not offer data; and/or (II) the study had inadequate sample size (i.e., the total number of patients who underwent surgery was $<200)$.

\section{Selection of literature}

After the database searches were completed, the retrieval results were imported into an Excel spreadsheet, and the title and abstract of the articles were read. Duplicate articles and articles that obviously failed to meet the criteria were excluded, and the full-text of the remaining articles was then retrieved. If the original text could not be obtained through the network, the original author of the article was contacted to obtain the full text. The full text of the articles was read for further screening.

\section{Data extraction}

For the eligible and included articles, the basic information, study characteristics, observation indicators, and outcome indicators of the articles were extracted by the researcher when reading the full text and recorded in an Excel table. If the data could not be obtained, as it was incomplete, 2 researchers performed crosschecks of the extracted data. The original authors of articles with incomplete data were contacted and the data were requested. If the data could not be obtained, the articles were excluded.

\section{Outcome indicators}

The data collected included the total number of study participants and the number of readmissions to the ICU, and patient characteristics, such as age, gender, body mass index (BMI) indicators, comorbidities, smoking habits, drinking habits, and the number of ICU admissions. The data were statistically analyzed. The outcome indicators 


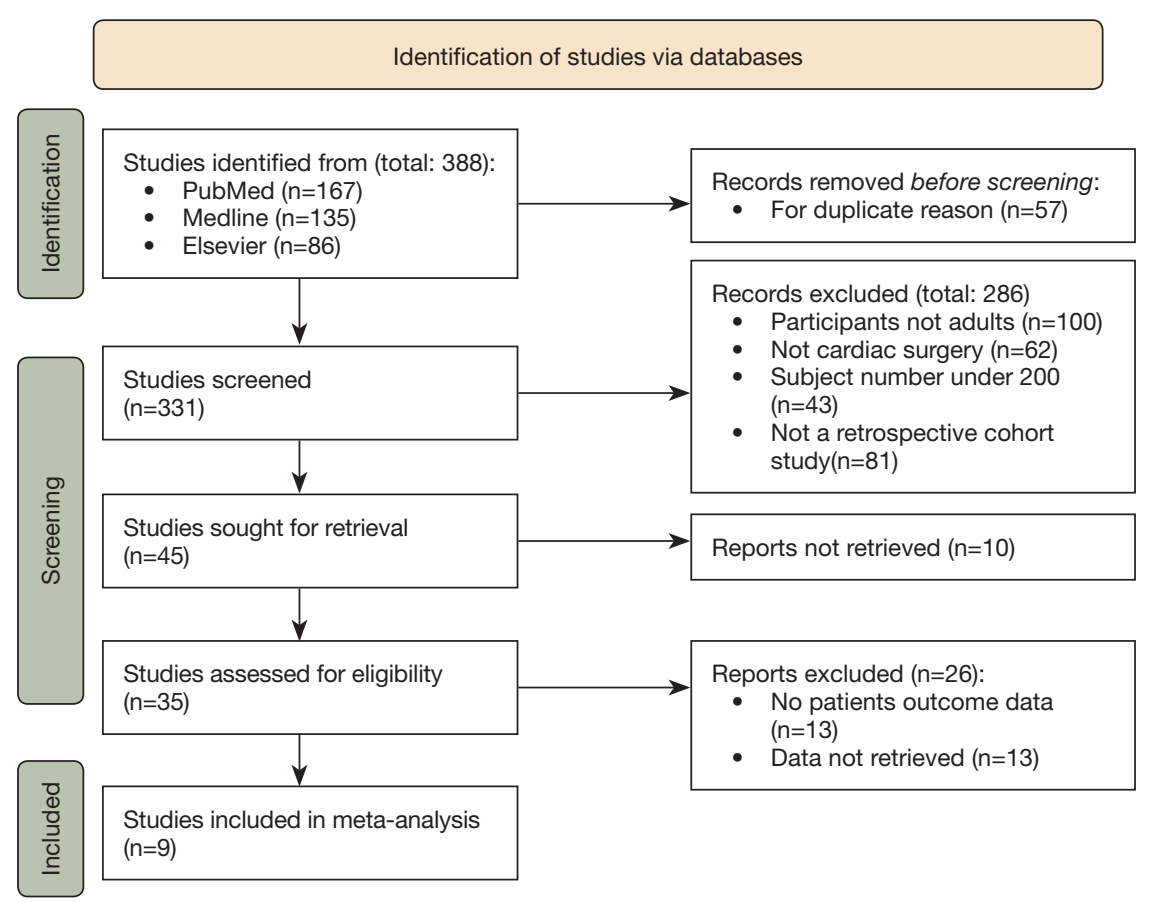

Figure 1 Search and selection chart.

included the mortality, length of ICU stay, and length of hospital stay in patients who were readmitted to the ICU compared to those who were not.

\section{Article quality assessment}

The quality of the included articles was evaluated using the Newcastle-Ottawa Scale (NOS) (8). The NOS was used to evaluate the subject selection, comparability, and outcome indicators of the articles. The maximum score was 9 points; a score of $>5$ points was considered good quality. The higher the score, the better the quality of the article, and the less the bias.

\section{Statistical analysis}

Stata16.0 software was used to analyze the data. For the binary variables of the mortality rate and the complication rate, the risk ratio (RR) value and the $95 \%$ confidence interval (CI) were used to report the combined effect size. For continuous variables, the standard mean difference (SMD) and 95\% CI were used to describe the effect size. Forest plots were obtained according to the results of the meta-analysis. A $\mathrm{P}$ value $<0.05$ indicated statistical significance. A homogeneity test was performed on the articles included in the study. A P value $>0.1$ or an $\mathrm{I}^{2}$ value $<50 \%$ indicated no heterogeneity in the articles. A fixedeffects analysis was conducted to calculate the $\mathrm{RD}$ value using the Mantel-Haenszel method. If heterogeneity existed, a random-effects analysis was conducted to calculate RD value using the Der Simonian and Laird method. Publication bias was described using a funnel plot.

\section{Heterogeneity investigation and sensitivity analysis}

We introduced subgroups to investigate the heterogeneity. If the results of the fixed-effects analysis were consistent with those of the random-effects analysis, the sensitivity analysis results were considered stable.

\section{Results}

\section{Article Search and screening results}

Three hundred and eighty-eight relevant articles were initially retrieved, 57 articles were then filtered out by duplication detection, and the remaining 331 articles were included in the primary screening. Ultimately, 9 articles (comprising 32,825 cardiac surgery cases) were included in the meta-analysis (see Figure 1). 
Table 1 Summary of basic characteristics of included articles and outcomes on ICU readmission

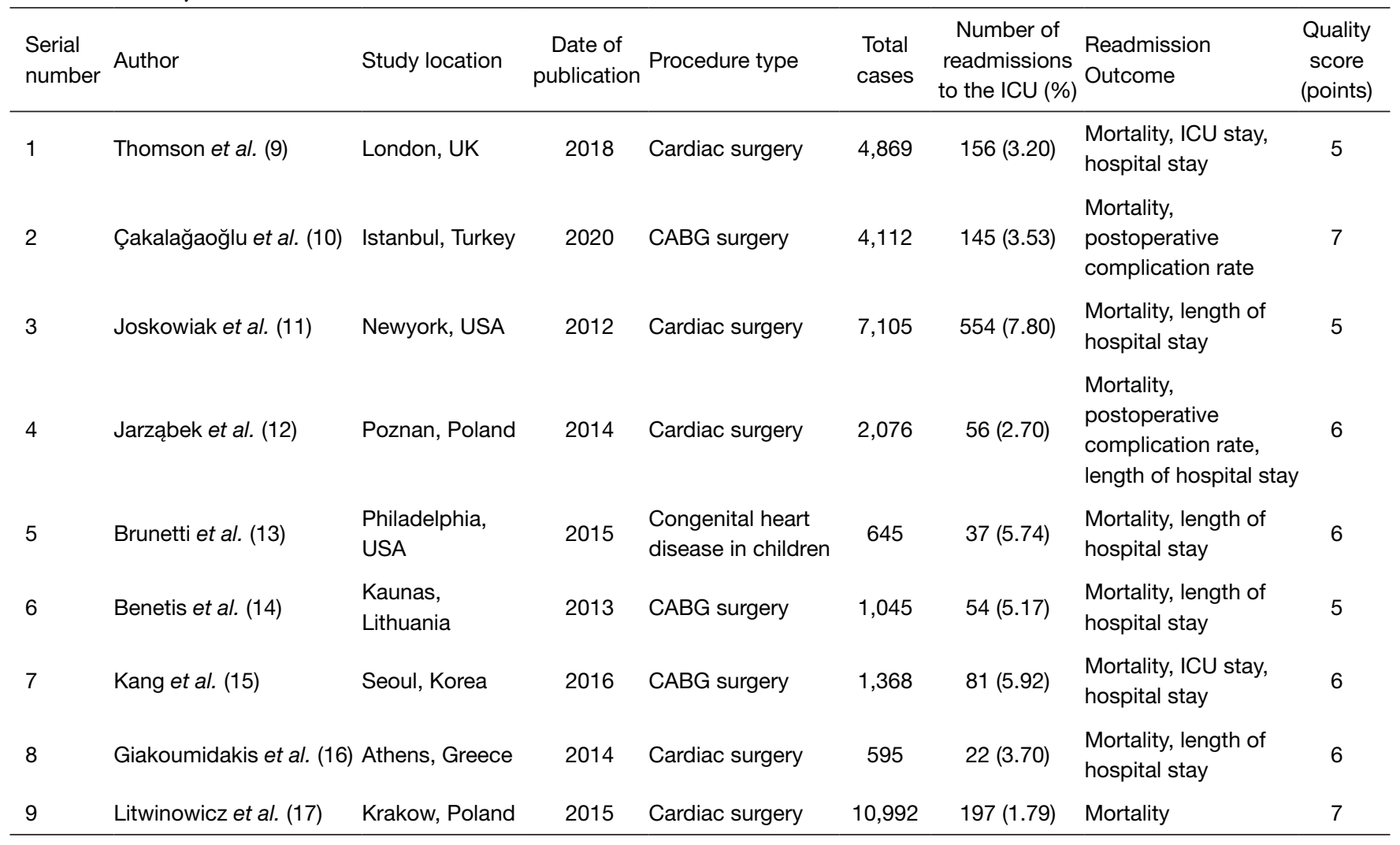

CABG, Coronary artery bypass graft; ICU, intensive care unit.

\section{Basic characteristics of articles}

A total of 9 retrospective cohort articles were included in this study. The total number of subjects ranged from 595 10,992, and 22-197 were readmitted to the ICU. The basic characteristics and NOR score of the included articles are shown in Table 1.

\section{Incidence of patient readmission to ICU}

Among the 9 included articles, the incidence rate of readmission to the ICU ranged from $1.79-7.80 \%$. Of the 32,825 cases, 1,302 were readmitted to the ICU, and the incidence rate of readmission to the ICU was $3.97 \%$.

\section{Comparison of outcomes of patients readmitted and not readmitted to the ICU}

\section{Mortality}

All 9 articles reported on the differences in the mortality rates between the patients readmitted to the ICU and those not readmitted to the ICU. There was heterogeneity between the articles $\left(\mathrm{I}^{2}=85.1 \% ; \mathrm{P}<0.001\right)$. The randomeffects analysis showed that the mortality rate of patients readmitted to the ICU was significantly higher than that of patients not readmitted to the ICU (RD $=8.05,95 \%$ CI: 5.10-12.69, $\mathrm{Z}=8.965 ; \mathrm{P}<0.0001)$.

The 9 articles were divided into the following 3 subgroups according to the type of surgery: (I) the general cardiac surgery group; (II) CABG group; and (III) pediatric congenital heart disease surgery group. The ICU reenrollment rate of pediatric congenital heart disease was higher than that of the CABG group (see Figure 2). Additionally, the 9 articles were divided into 3 subgroups according to the study sites (i.e., Europe, Asia, or America). The ICU reenrollment rate was found to be higher in American patients, followed by Asian and then European patients (see Figure 3).

\section{Length of hospital stay}

Six articles $(9,11-15)$ compared the length of hospital stay between patients readmitted to the ICU and patients not 


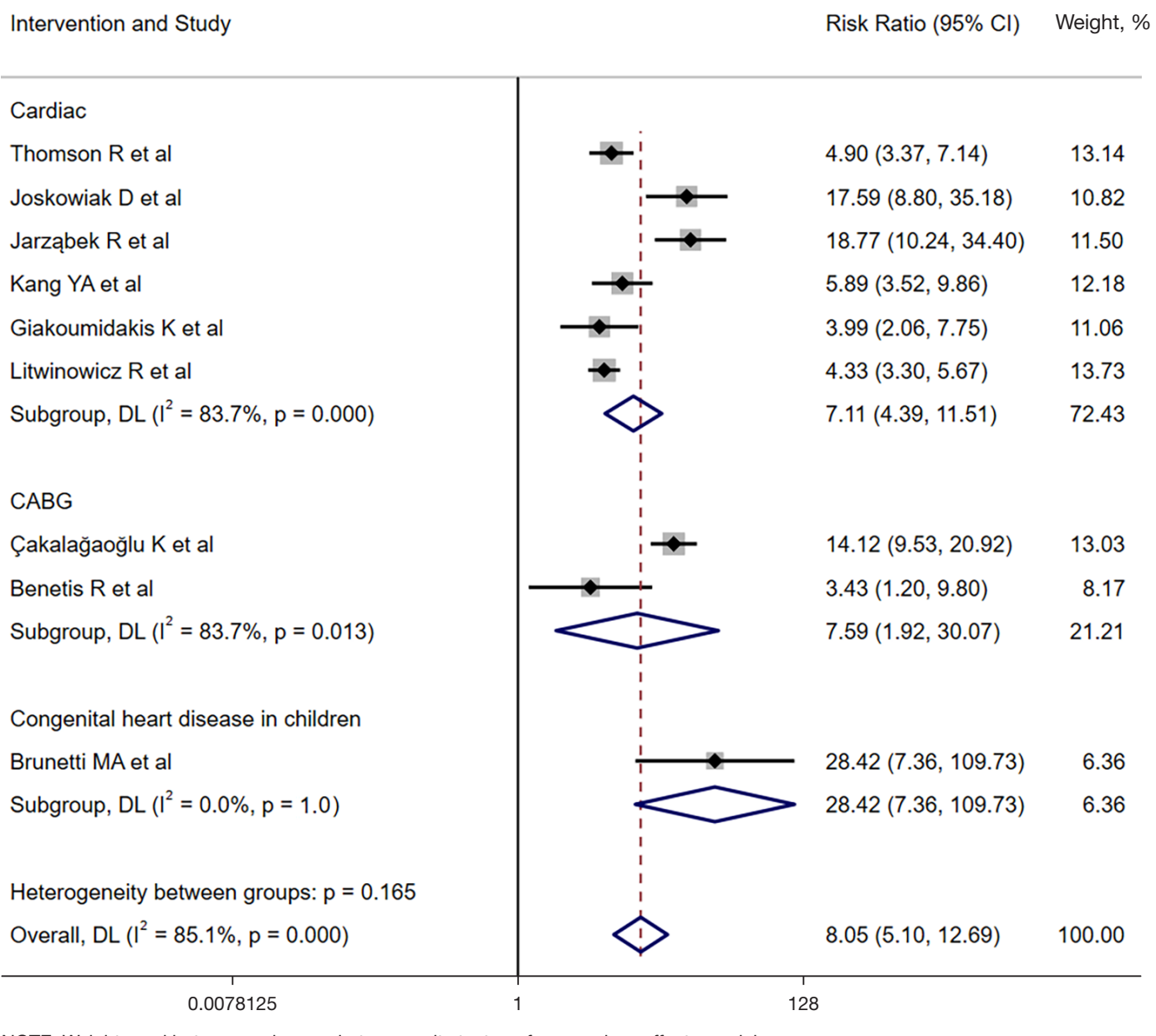

NOTE: Weights and between-subgroup heterogeneity test are from random-effects model

Figure 2 Comparison of mortality in patients readmitted to the ICU and those not readmitted (grouped by type). CABG, coronary artery bypass graft.

readmitted to the ICU. There was heterogeneity between the articles $\left(\mathrm{I}^{2}=99.7 \%, \mathrm{P}<0.001\right)$. The random-effects analysis showed that the length of hospital stay of patients readmitted to the ICU was significantly higher than that of patients not readmitted to the ICU (SMD $=3.17,95 \% \mathrm{CI}$ : 1.40-4.94, $\mathrm{Z}=3.504, \mathrm{P}<0.001$; see Figure 4).

\section{Postoperative complication rate}

Three articles $(10,14,15)$ reported on the incidence rate of postoperative complications in patients readmitted to the ICU and patients not readmitted to the ICU. There was no heterogeneity between the articles $\left(\mathrm{I}^{2}=0 \%, \mathrm{P}=0.74\right)$. The random-effects analysis showed that the incidence rate of postoperative patients readmitted to the ICU was significantly higher than that of patients not readmitted to the ICU (RR
$=1.97,95 \%$ CI: 1.35-2.87, Z=3.507; $\mathrm{P}<0.001$; see Figure 5).

\section{Specific reasons for patient readmission to ICU}

All the included articles specified the reasons why patients were readmitted to the ICU. Of these reasons, respiratory failure accounted for $13.6-48.6 \%$, and hemodynamic instability accounted for $21.6-51.9 \%$ (see Table 2).

\section{Heterogeneity investigation and sensitivity analysis}

As Figure 5 shows, after the 9 articles were grouped according to the type of surgery, there was still significant heterogeneity in the 2 subgroups. There may be multiple sources of heterogeneity, including region, race, and age. 
Location and Study

Risk Ratio $(95 \% \mathrm{Cl})$ Weight, \%

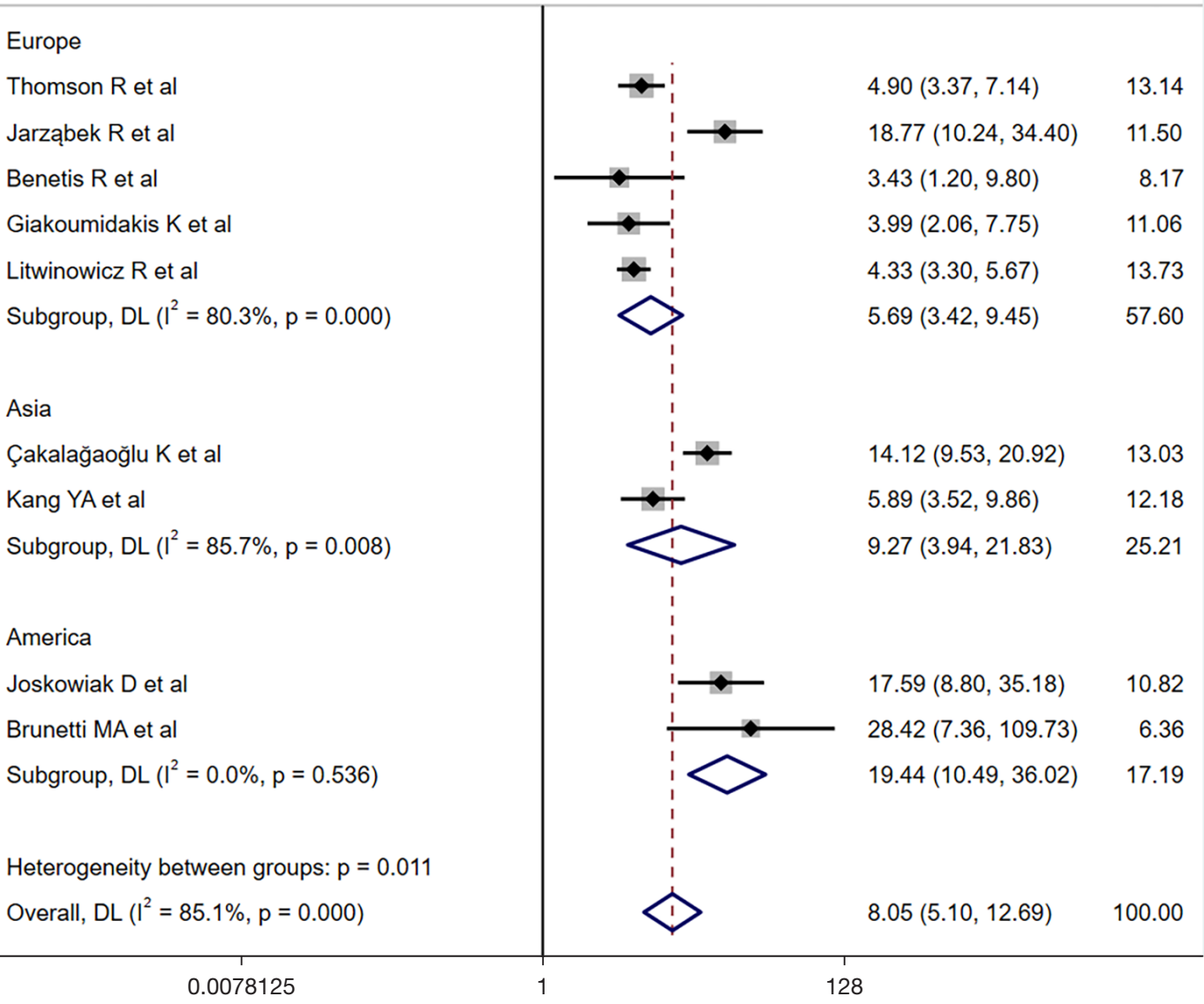

NOTE: Weights and between-subgroup heterogeneity test are from random-effects model

Figure 3 Comparison of mortality between patients readmitted to the ICU and those not readmitted (grouped by region).

Study

Effect $(95 \% \mathrm{Cl}) \quad$ Weight, \%

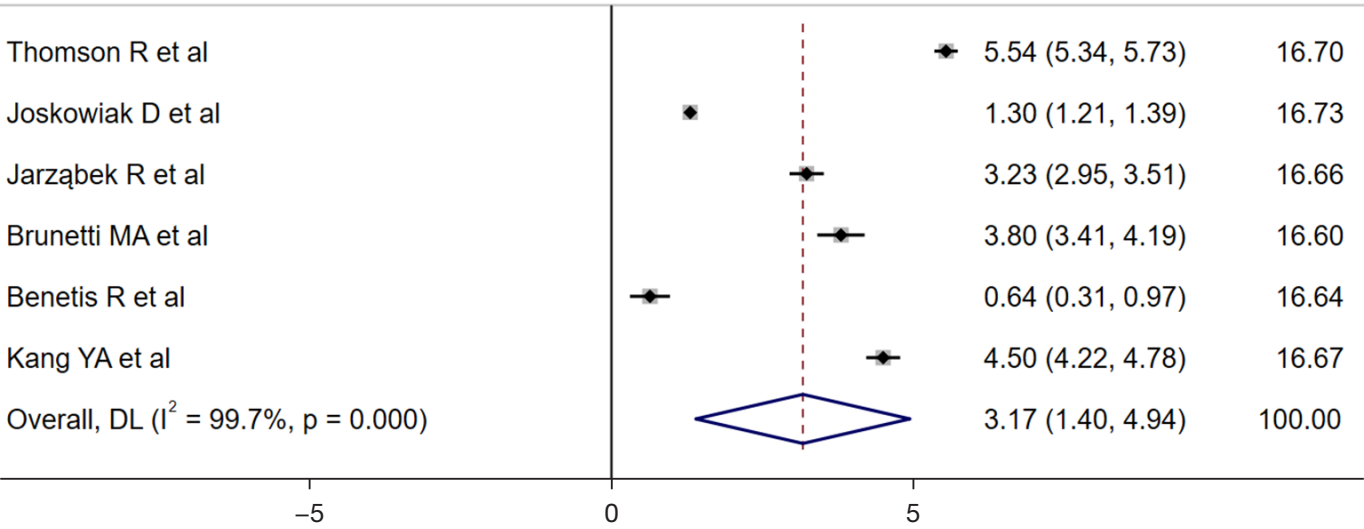

NOTE: Weights are from random-effects model

Figure 4 Comparison of the length of hospital stay between patients readmitted to the ICU and those not readmitted. 


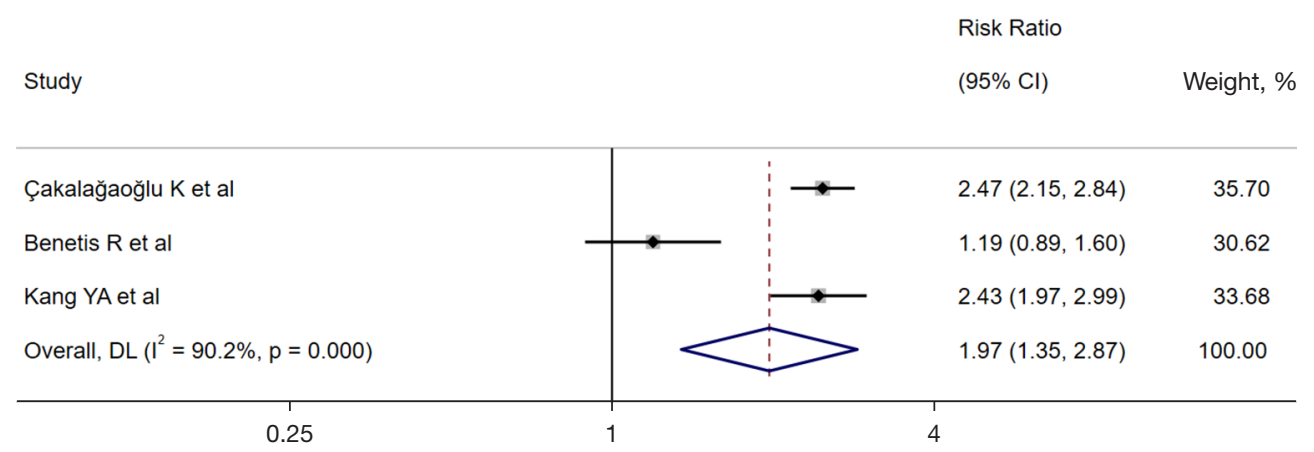

NOTE: Weights are from random-effects model

Figure 5 Comparison of the incidence of postoperative complications between patients readmitted to the ICU and those not readmitted.

Table 2 Analysis of specific reasons for readmission to ICU

\begin{tabular}{|c|c|c|c|c|c|c|}
\hline $\begin{array}{l}\text { Serial } \\
\text { number }\end{array}$ & Author & $\begin{array}{l}\text { Number of } \\
\text { readmissions to ICU }\end{array}$ & \multicolumn{4}{|c|}{ Reason for ICU readmission (\%) } \\
\hline 1 & Thomson et al. (9) & 156 & $52(33.3)$ & $36(23.1)$ & $22(14.1)$ & $42(26.9)$ \\
\hline 2 & Çakalağaoğlu et al. (10) & 145 & $42(29.0)$ & $34(23.5)$ & $27(18.6)$ & $42(29.0)$ \\
\hline 3 & Joskowiak et al. (11) & 554 & $216(39.0)$ & $145(26.2)$ & - & - \\
\hline 5 & Brunetti et al. (13) & 37 & $18(48.6)$ & $8(21.6)$ & $3(8.1)$ & $8(21.6)$ \\
\hline 6 & Benetis et al. (14) & 54 & $16(29.6)$ & $27(50.0)$ & $5(9.3)$ & $6(11.1)$ \\
\hline 7 & Kang et al. (15) & 81 & $11(13.6)$ & $42(51.9)$ & $4(4.9)$ & $24(29.6)$ \\
\hline 8 & Giakoumidakis et al. (16) & 22 & $10(45.4)$ & $6(27.3)$ & $2(9.1)$ & $4(18.2)$ \\
\hline
\end{tabular}

\section{Publication bias analysis}

As Figure 6 shows, to compare the mortality rate of patients readmitted to the ICU to that of patients not readmitted to the ICU, the included 9 articles showed an uneven distribution on the left and right, which suggests publication bias.

\section{Discussion}

Clinically, reports in various regions on the number of patients readmitted to the ICU after cardiac surgery vary, and have reached as high as $19 \%$ (18-20). In a meta-analysis by Hughes et al. (21) of 4,417 patients with surgically corrected coronary heart disease, the proportion of patients readmitted to the ICU was $10.2 \%$. One comprehensive study (17) with a large sample size of 10,992 adult cardiac surgery patients, reported that the incidence rate of readmission to the ICU was $1.79 \%(197 / 10,992)$. In our study, 9 relevant articles (comprising 32,825 subjects) were included in the meta-analysis. The incidence rate of readmission to the ICU was $3.97 \%$. The reasons for readmission of patients to the ICU were analyzed, and hemodynamic instability and respiratory failure were cited as the most important reasons. The former included patients who had undergone sudden cardiac arrest caused by ventricular fibrillation or cardiac arrest, and other patients with hypotension caused by persistent arrhythmia or heart failure who were unresponsive to treatment, while the latter included various patients who required mechanical ventilation for assisted respiration due to respiratory failure.

This study also found that patients readmitted to the ICU had significantly higher mortality, more complications, and longer hospital stays than those not readmitted to the 


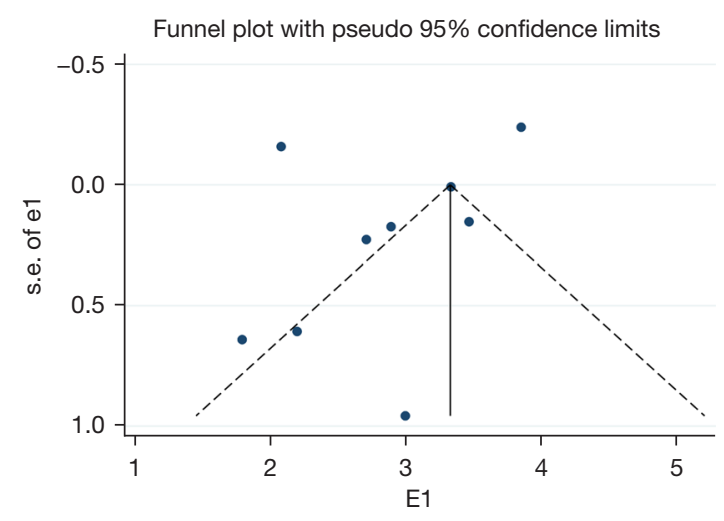

Figure 6 Funnel plot of mortality, E1, the effect size of mortality.

ICU. Further, readmission to the ICU usually meant a significant change in condition, which was associated with a variety of factors, such as patient age, cardiac function, renal function, therapeutic drugs, and surgical trauma (22).

In this study, patients were divided into groups according to the type of surgery, and the results showed that the ICU readmission rate of pediatric congenital heart disease was higher than that of the CABG group, and the ICU readmission rate was higher for American patients than Asian and European patients; however, the quality of evidence was low due to the small number of included articles.

In this meta-analysis, heterogeneity was found among the articles in the analysis of mortality. After the subgroup analysis and investigation, there was still significant heterogeneity among the patients grouped by region and type of surgery. The heterogeneity may be due to a number of factors, including region, race, the surgical method, and age. The asymmetric distribution on both sides of the funnel plot suggests that there may be a reporting bias, which meant people might have bias towards reporting mortality, length of hospital stay, complications for readmission patients. For the investigation of patient readmission to ICU, more articles with high-quality evidence need to be retrieved to provide stronger evidence of the readmission rate of ICU after cardiac surgery.

\section{Conclusions}

It will assist readers if this is stated. total of 9 articles were included in this meta-analysis on the incidence rate of readmission to the ICU of patients who had undergone cardiac surgery. The results showed that the proportion of readmission to the ICU was $3.97 \%$ for patients who had undergone cardiac surgery. The patients who were readmitted to the ICU had a higher incidence rate of complications, length of hospital stay, and mortality than those not readmitted to the ICU.

\section{Acknowledgments}

Funding: This project was supported by Hainan Province Clinical Medical Center.

\section{Footnote}

Reporting Checklist: The authors have completed the MOOSE reporting checklist. Available at https://jtd. amegroups.com/article/view/10.21037/jtd-21-1893/rc

Conflicts of Interest: All authors have completed the ICMJE uniform disclosure form (available at https://jtd.amegroups. com/article/view/10.21037/jtd-21-1893/coif). The authors have no conflicts of interest to declare.

Ethical Statement: The authors are accountable for all aspects of the work in ensuring that questions related to the accuracy or integrity of any part of the work are appropriately investigated and resolved.

Open Access Statement: This is an Open Access article distributed in accordance with the Creative Commons Attribution-NonCommercial-NoDerivs 4.0 International License (CC BY-NC-ND 4.0), which permits the noncommercial replication and distribution of the article with the strict proviso that no changes or edits are made and the original work is properly cited (including links to both the formal publication through the relevant DOI and the license). See: https://creativecommons.org/licenses/by-nc-nd/4.0/.

\section{References}

1. Kolat P, Guttenberger P, Ried M, et al. ICU Readmission after Cardiac Surgery-Still a Matter of Concern? Thorac Cardiovasc Surg 2020;68:384-8.

2. Lomivorotov V, Kornilov I, Boboshko V, et al. Effect of Intraoperative Dexamethasone on Major Complications and Mortality Among Infants Undergoing Cardiac Surgery: The DECISION Randomized Clinical Trial. JAMA 2020;323:2485-92.

3. Lal S, Gray A, Kim E, et al. Frailty in Elderly Patients 
Undergoing Cardiac Surgery Increases Hospital Stay and 12-Month Readmission Rate. Heart Lung Circ 2020;29:1187-94.

4. Smischney NJ, Shaw AD, Stapelfeldt WH, et al. Postoperative hypotension in patients discharged to the intensive care unit after non-cardiac surgery is associated with adverse clinical outcomes. Crit Care 2020;24:682.

5. Li S, Tang BY, Zhang B, et al. Analysis of risk factors and establishment of a risk prediction model for cardiothoracic surgical intensive care unit readmission after heart valve surgery in China: A single-center study. Heart Lung 2019;48:61-8.

6. Magruder JT, Kashiouris M, Grimm JC, et al. A Predictive Model and Risk Score for Unplanned Cardiac Surgery Intensive Care Unit Readmissions. J Card Surg 2015;30:685-90.

7. Shawon MSR, Odutola M, Falster MO, et al. Patient and hospital factors associated with 30-day readmissions after coronary artery bypass graft (CABG) surgery: a systematic review and meta-analysis. J Cardiothorac Surg 2021;16:172.

8. Stang A. Critical evaluation of the Newcastle-Ottawa scale for the assessment of the quality of nonrandomized studies in meta-analyses. Eur J Epidemiol 2010;25:603-5.

9. Thomson R, Fletcher N, Valencia O, et al. Readmission to the Intensive Care Unit Following Cardiac Surgery: A Derived and Validated Risk Prediction Model in 4,869 Patients. J Cardiothorac Vasc Anesth 2018;32:2685-91.

10. Çakalağaoğlu KC, Selçuk E, Erdem H, et al. Analysis of Readmissions to The Intensive Care Unit After Coronary Artery Bypass Surgery: Ten Years' Experience. Braz J Cardiovasc Surg 2020;35:732-40.

11. Joskowiak D, Wilbring M, Szlapka M, et al. Readmission to the intensive care unit after cardiac surgery: a singlecenter experience with 7105 patients. J Cardiovasc Surg (Torino) 2012;53:671-6.

12. Jarząbek R, Bugajski P, Greberski K, et al. Readmission to an intensive care unit after cardiac surgery: reasons and outcomes. Kardiol Pol 2014;72:740-7.

13. Brunetti MA, Glatz AC, McCardle K, et al. Unplanned

Cite this article as: $\mathrm{Lv} \mathrm{H}$, Meng Z, Yu C, Chen Q, Wang $\mathrm{Y}, \mathrm{Xiao} \mathrm{Y}$. Incidence of readmission to the ICU after cardiac surgery: a systematic review and meta-analysis. J Thorac Dis 2022;14(2):414-422. doi: 10.21037/jtd-21-1893
Readmission to the Pediatric Cardiac Intensive Care Unit: Prevalence, Outcomes, and Risk Factors. World J Pediatr Congenit Heart Surg 2015;6:597-603.

14. Benetis R, Sirvinskas E, Kumpaitiene B, et al. A casecontrol study of readmission to the intensive care unit after cardiac surgery. Med Sci Monit 2013;19:148-52.

15. Kang YA. Risk Factors and Outcomes Associated With Readmission to the Intensive Care Unit After Cardiac Surgery. AACN Adv Crit Care 2016;27:29-39.

16. Giakoumidakis K, Eltheni R, Patelarou A, et al. Incidence and predictors of readmission to the cardiac surgery intensive care unit: A retrospective cohort study in Greece. Ann Thorac Med 2014;9:8-13.

17. Litwinowicz R, Bartus K, Drwila R, et al. In-hospital mortality in cardiac surgery patients after readmission to the intensive care unit: a single-center experience with 10,992 patients. J Cardiothorac Vasc Anesth 2015;29:570-5.

18. Zhong J, Gao J, Luo JC, et al. Serum creatinine as a predictor of mortality in patients readmitted to the intensive care unit after cardiac surgery: a retrospective cohort study in China. J Thorac Dis 2021;13:1728-36.

19. Boreland L, Scott-Hudson M, Hetherington K, et al. The effectiveness of tight glycemic control on decreasing surgical site infections and readmission rates in adult patients with diabetes undergoing cardiac surgery: A systematic review. Heart Lung 2015;44:430-40.

20. Liu Y, Zhao Y, Tian J, et al. The association of depression following percutanous coronary intervention with adverse cardiovascular events: Protocol for a systematic review and meta-analysis. Medicine (Baltimore) 2019;98:e13952.

21. Hughes A, Carter K, Cyrus J, et al. Pleural Effusions After Congenital Cardiac Surgery Requiring Readmission: A Systematic Review and Meta-analysis. Pediatr Cardiol 2020;41:1145-52.

22. Arora RC, Manji RA, Singal RK, et al. Outcomes of octogenarians discharged from the hospital after prolonged intensive care unit length of stay after cardiac surgery. J Thorac Cardiovasc Surg 2017;154:1668-1678.e2.

(English Language Editor: L. Huleatt) 